\title{
Propositionalism without propositions, objectualism without objects
}

\section{Angela Mendelovici}

Draft January 10, 2017

Forthcoming in 2018 in Non-Propositional Intentionality, ed. Alex Grzankowski and Michelle Montague, OUP

\begin{abstract}
Propositionalism is the view that all intentional states are propositional states, which are states with a propositional content, while objectualism is the view that at least some intentional states are objectual states, which are states with objectual contents, such as objects, properties, and kinds. This chapter argues that there is a distinction between the deep nature of intentional states and contents, which is what they really are, metaphysically speaking, and their superficial characters, which are the superficial features that characterize them as the intentional states or contents that they are. This chapter argues that there are two corresponding ways of understanding the debate between propositionalism and objectualism: (1) as a debate over whether there are intentional states with objectual deep natures, and (2) as a debate over whether there are intentional states with objectual superficial characters. I argue that we should understand the debate in the second way. I also argue that the propositionalism debate is fairly independent from debates over the deep nature of intentionality, and that this has implications for arguments for propositionalism and objectualism from claims about the nature of intentional content. I close with a brief discussion of how related points apply to the debate over singular content.
\end{abstract}

\section{Introduction}

Propositionalism is the view that all intentional states are propositional states, which are states with a propositional content. An example of a propositional state is the belief that grass is green, which has the propositional content grass is green. The alternative view, objectualism, is the view that at least some intentional states are objectual states, which are states with objectual contents, such as objects, properties, and kinds. An example of an objectual state might be the state of loving Eleni, which has the objectual content Eleni. Objectualists claim that there are at least some such states with objectual contents. Other examples of intentional states that have been claimed to have objectual contents are desires, 
likings, and fears. Propositionalists, of course, do not deny the existence of states of loving, desiring, liking, and fearing. But they maintain that, perhaps contrary to appearances, these states have propositional contents. For example, they might claim that the state of loving Eleni has propositional contents like Eleni is $F$, for some $\mathrm{F}$.

This chapter argues that there are two distinct ways of understanding propositionalism and objectualism: on one way, they are views about the deep nature of the contents of intentional states, about what those states really are, metaphysically speaking. On the other way, they are views about the superficial character of the contents of intentional states, about the superficial features that characterize them as the intentional states or contents that they are. I recommend understanding the debate in the second way. I also argue that the debate is fairly independent of debates over the deep nature of intentionality, and that this has implications for arguments for propositionalism and objectualism from claims about the nature of intentional content. I close with a brief discussion of how related points apply to the debate over singular content.

\section{Intentionality and the deep nature and superficial character of content}

Since propositionalism and objectualism are views about intentional states, it is important to get clear on what intentionality is.

We can fix reference on intentionality ostensively: Some mental states have features that we notice introspectively and that we are tempted to describe using representational terms such as "of," "about," "says," "directed," "presents," or "represents." For example, we might describe a thought as "saying" that grass is green, or a visual experience as being "about" or "of" a blue square or a coffee mug. Intentionality is this feature of mental states that we at least sometimes notice in ourselves and that we are tempted to describe using representational language like "of" and "about." Intentional states are mental states exhibiting intentionality. What an intentional state "says," "presents," or is "about," or, more generally, what it represents, is its (intentional) content. ${ }^{1}$

This way of fixing reference on intentionality fixes reference on a feature of mental states by pointing to instances of that feature that we can notice introspectively in ourselves. Of course, this does not mean that every instance of intentionality must be introspectively accessible; there might be nonconscious instances of intentionality or conscious instances of intentionality that we cannot introspect upon. This way of fixing reference on intentionality also does not preclude the existence of non-mental instances of intentionality, e.g. in language. Nonconscious, introspectively inaccessible, and non-mental instances of intentionality, if there are such, would count as instances of intentionality because they would

\footnotetext{
${ }^{1}$ Such ostensive ways of fixing reference on intentionality have been defended by Mendelovici (2010, ch. 2 , 2018, ch. 1) and Kriegel (2011, Ch. 1).
} 
be instances of the very same mental feature that we observe in our paradigm cases (which are, presumably, conscious, introspectively accessible, and mental).

One of the virtues of this way of fixing reference on intentionality is that it allows us to remain fairly neutral on many of the putative features of intentionality. Intentionality is sometimes thought to play various roles in folk psychology and cognitive science. Some approaches to fixing reference on intentionality take intentionality to be defined by such roles. But as far as our ostensive way of fixing reference on intentionality is concerned, we can remain neutral on whether intentionality plays any such roles, and thus on the status of folk psychology and cognitive scientific theories making reference to intentionality. As long as our introspective observations latch onto something, we can successfully fix reference on it, even if what we latch onto fails to play the roles intentionality is sometimes thought to play. $^{2}$

I want to now draw a distinction between what I will call the "deep nature" and the "superficial character" of intentional states and contents. In order to motivate this distinction, it is helpful to first consider an analogy: There are different questions we might ask about furniture. We might ask deep, metaphysical questions about the nature of furniture. For example, we might ask if pieces of furniture have physical or functional natures, or if their existence is dependent on minds or people. We can ask if being a piece of furniture is an intrinsic property or an extrinsic, perhaps historical or social, property. And we can ask how pieces of furniture are related to the matter that constitutes them. All these questions are questions about the "deep nature" of furniture, about what furniture really is, metaphysically speaking.

There is a different set of questions we might ask about furniture: We might ask what kind of piece of furniture some piece of furniture belongs to, e.g. whether it is a table, a bed, or a chair. We can ask questions about the uses or functions of certain types of furniture, such as whether futons are used for sleeping, sitting, or both. And we can ask questions about certain relations between different kinds of furniture, such as whether couches are generally bigger than loveseats, or whether tables are usually accompanied by chairs. These are all questions about what we might call the "superficial" features of furniture.

The two types of questions are largely independent. We can answer questions about the deep nature of furniture without answering the question of whether what I have in my living room is a chair or a stool, and we can identify the piece of furniture in my living room as a chair while remaining noncommittal on whether what makes it a chair is the use I put it to or its historical relations to the manufacturer.

I want to suggest that we can draw a parallel distinction between the "deep" and "superficial" features of intentionality. The (deep) nature of intentional states and contents is what they really are, at bottom, metaphysically speaking. There are various views of the deep

\footnotetext{
${ }^{2}$ See Mendelovici 2018, ch. 1 for further development of these points.
} 
nature of intentional states: One view is that they are states of bearing tracking relations to worldly objects and properties. Another view takes them to be states of bearing primitive relations to abstract sets of possible worlds. A third view takes intentional states to be adverbial modifications of subjects. Here are some corresponding views of the deep nature of intentional contents: One view is that contents are concrete worldly objects and properties. Another is that contents are sets of possible worlds. A third is that contents are second-order properties of intentional states, or ways of representing.

The (superficial) characters of intentional states and contents are the superficial features that characterize them as the intentional states or contents that they are. Views about the particular contents of particular intentional states are views about their superficial characters. For example, the view that Justin Trudeau is currently thinking that grass is green is a view about the superficial character of his intentional states, not a view about their deep nature. Some views that make generalizations about certain types of intentional states are also views about their superficial characters. For example, the view that there are thoughts that have contents that perceptual states cannot have is a view about the superficial characters of thoughts and perceptual states. The view that nonconscious intentional states have vague or indeterminate contents is likewise a view about the superficial characters of nonconscious thoughts. Similarly, the view that Oscar and his Twin Earth duplicate, Toscar, have waterystuff-related thoughts with different contents is a view about the superficial character of Oscar and Toscar's watery-stuff-related thoughts. ${ }^{3}$

As in the furniture case, we can investigate the deep nature of intentional states and contents largely independently of investigating their superficial character, and vice versa. For example, we might wonder how many different color contents human beings can visually represent and how these color contents might be organized based on similarity. We can answer these questions using verbal reports of the perceived similarities and differences of color patches. This kind of project needn't concern itself with questions surrounding the nature of the content of color experience. For instance, it needn't worry about whether color contents are abstract properties, sense data, adverbial modifications of subjects, or ideas in the mind of God. However, this is not to say that there cannot be incompatibilities or tensions between certain views of the nature and character of intentional states and contents (more on this later).

Before moving on, I want to suggest that two ways in which we can know about our intentional states, through introspection and from observations of psychological role, most clearly tell us about their superficial characters, not their deep natures.

We used introspection to get an ostensive grip on intentionality, but introspection can tell us more than that we have intentional states. At least sometimes, and at least to a certain

\footnotetext{
${ }^{3}$ Oscar and Toscar (or "Twin Oscar") are the well-known protagonists of Putnam's (1975) Twin Earth thought experiment.
} 
extent, introspection can tell us which intentional states we have, though it does not reveal to us their deep nature. For example, introspection can tell you that you are currently thinking that grass is green, rather than that snow is white, or that you are perceptually experiencing a red ball rolling off a table, rather than a pink elephant sulking in the corner. But introspection does not reveal to you the deep nature of your thought or its content. For example, it does not tell you whether the content grass is green is a set of possible worlds, an ordered pair of properties and real-world objects, or an adverbial modification of subjects. ${ }^{4}$

Note that this is not to say that introspection can tell us which contents any given intentional state represents. Introspection presumably cannot tell us what nonconscious states represent, and it might have only limited access to broad states, which have their contents at least partly determined by our relations to our environments.

This is also not to say that in introspection we are not, at least sometimes, presented with our contents in their entirety. Perhaps what we are presented with in introspection is an ordered pair of properties and objects, but we are not able to use our introspective experience alone to tease apart these components. We can use introspection to discern the superficial character of our contents, to tell us which contents we represent, but not to reveal their deep nature. Note that the claim that introspection does not reveal the deep nature of intentional states and contents does not preclude the possibility of using introspective evidence in conjunction with other evidence or a priori reasoning to draw inferences about the deep nature of intentionality. For example, one might argue that certain theories of the deep nature of intentionality are incompatible with the facts concerning which particular contents we represent.

A second way in which we can learn about our intentional states and their contents is by considering their psychological role. A subject's inferences and behaviors are evidence as to what content she is representing. Again, what this sort of evidence can tell us about, at least in the first instance, is the superficial character of a subject's contents, not their deep nature. For example, Maria's bringing an umbrella to work is evidence that she believes it might rain today, but it is not evidence for or against the view that she has an intentional state whose contents are sets of possible worlds.

Again, it might be that not all aspects of an intentional state's superficial character are reflected in its psychological role. For example, Oscar and Toscar's water concepts might be alike with respect to their psychological roles, but represent different contents, so at least some aspects of their contents are occluded from considerations of psychological role. Additionally, although considerations of psychological role in the first instance only tell us

\footnotetext{
${ }^{4}$ The situation is similar to the situation concerning phenomenal consciousness, the "what it's like" aspect of mental life. Introspection can reveal the character of phenomenal states without revealing their natures. For example, introspection might reveal that an after-image has a reddish-roundish phenomenal character without revealing whether its nature is that of being a brain state, a functional state, a primitive state, or something else. Note that this is to deny what is sometimes called "revelation" (see e.g. Goff 2017).
} 
about the superficial character of intentional states and contents, this does not preclude the possibility of using considerations about psychological roles to draw inferences about the deep nature of intentionality. For example, one might argue that, in order for intentionality to have any psychological role at all, it must be a non-relational feature of subjects.

I have argued that there is a distinction between the deep nature and the superficial character of intentional states, and that two key ways of finding out about intentional states primarily tell us about their superficial characters rather than their deep natures. Let us now see how all this can help us clarify the debate over propositionalism.

\section{Two ways of understanding propositionalism and objectualism}

On our first pass characterization of propositionalism, it is the view that all intentional states are propositional states, which are states with a propositional content. On our first pass characterization of the alternative view, objectualism, it is the view that at least some intentional states are objectual states, which are states with non-propositional (or objectual) contents, such as objects, properties, and kinds. The disagreement over the two views concerns the contents of intentional states. Propositionalism maintains that the contents of all intentional states have a certain feature, that of being propositional, whereas objectualism maintains that the contents of at least some intentional states lack this feature; they have a different feature, that of being objectual. In order to get clear on what exactly propositionalism and objectualism are, we need to ask: What exactly are these features? What is it for a content to be propositional or objectual?

There are two general ways of understanding what it is for a content to be propositional or objectual. On the first way, being propositional and being objectual are features of the deep nature of contents. This makes propositionalism and objectualism views about the deep nature of contents, views on which all contents have a propositional or an objectual nature, respectively. On the second way, being propositional and being objectual are features of the superficial character of contents. This makes propositionalism and objectualism views about the superficial character of contents, views on which all contents have a propositional or an objectual superficial character, respectively. This section explores these two ways of understanding what it is for a content to be propositional.

On the first way of understanding what it is for a content to be propositional, propositional contents are contents with a propositional nature. It is not clear just what it would take to have a propositional nature, but the following kinds of entities should count as having one: abstract or concrete sets of possible worlds, sets of sentences, states of affairs, and structured propositions consisting of concrete objects and properties. On this way of understanding propositionalism, it is the view that all contents have a propositional nature. Call this view deep propositionalism. On the corresponding way of understanding what it is for a content to be objectual, objectual contents are contents with an objectual nature, where items like concrete objects, possible objects, Meinongian objects, abstract properties, sets of concrete property instances, and the like should count as contents with an objectual nature. 
The resulting understanding of objectualism, which we might call deep objectualism, is the view that at least some contents have an objectual nature.

Since both entities of a propositional nature and entities of an objectual nature are taken by these views to exist distinctly of our representing them, deep propositionalism and deep objectualism are both committed to a relational view of the nature of intentional states, on which intentionality is a relation to distinctly existing entities playing the role of contents. So, an alternative way of characterizing deep propositionalism is as the view that all intentional states are relations to contents with a propositional nature, and an alternative way of characterizing deep objectualism is as the view that some intentional states are relations to contents with an objectual nature.

Here are some examples of characterizations of propositionalism that are suggestive of deep propositionalism:

Starting with Russell, mental states such as believing, desiring, hoping, etc., have often been characterized as propositional attitudes ... Some [philosophers] took mental states to be relations to propositions, the latter preferably construed as abstract objects; and others took mental states to be relations to sentences. (Ben-Yami, 1996, 84 , footnotes suppressed)

[A]ttitudes are essentially relational in nature: they involve relations to the propositions at which they are directed. (Perry 1994, 387-8)

"Propositionalism" is the widely held view that all intentional mental relations - all intentional attitudes - are relations to propositions or something proposition-like. (Montague 2007, 503)

[D]esires are propositional attitudes. On this view, the real intentional object of any desire is a proposition, and the desire itself is a particular kind of attitude towards that proposition. Some desires wear their propositional structure on their sleeves. For instance, my current desire that you find this chapter illuminating relates me, the desirer, to the proposition "You find this essay illuminating." (Brewer 2006, 260)

Although these quotations are suggestive of deep propositionalism, it is not clear that their authors take deep propositionalism to be their target. We will soon see that some passages from the same authors are suggestive of an alternative way of understanding what it is for a content to be propositional.

The alternative way of understanding what it is for a content to be propositional takes a propositional content to be a content with a propositional superficial character, where a content has a propositional (superficial) character just in case it represents that something is the case. An example of an intentional state with a propositional character is the belief that grass is green, which has the content grass is green. This intentional state represents that something is the case, namely that grass is green. States with a propositional character can be contrasted with states with an objectual (superficial) character, which merely represent objects, properties, kinds, or the like. For example, the state of loving Eleni, it might be argued, has as its content Eleni, which is a content with an objectual character; it is not a love 
of something being the case. Likewise, a fear of clowns, it might be argued, has the content clowns, which is a content having an objectual character. Like the state of loving Eleni, it is not a fear that something is the case.

On this understanding of what it is for a content to be propositional, being propositional is a feature of the superficial character of intentional contents rather than a feature of their deep nature. The resulting understanding of propositionalism, which we might call shallow propositionalism, is the view that all intentional contents have a propositional character. The resulting understanding of objectualism, which we might call shallow objectualism, is the view that at least some intentional contents have an objectual character.

Dretske's characterization of propositionalism suggests a shallow version of the view:

It may be, as some have argued, that we cannot know, remember, or perceive a thing without knowing, remembering, or perceiving some fact about that thing. According to this view, what we know, perceive, and remember is always propositional in character. (Dretske 1980, 354)

Setting aside his apparent commitment to a relational view of intentionality, Brewer expresses something like the above conception of propositional states:

To claim that desires are propositional attitudes is to commit oneself to the claim that any desire can be expressed fully, without distortion or loss, as a desire that thus-andsuch. (Brewer 2006, 260)

Again, setting aside her apparent commitment to a relational view of intentionality, Montague characterizes propositionalism as the view that all intentional states are discursive in form, which is suggestive of shallow propositionalism:

To have an intentional attitude to anything, on this view, is to be related to something that is (so to say) essentially discursive in form, i.e. something whose nature can only be perspicuously conveyed by a verb-involving sentence. (Montague 2007, 503, emphasis in original)

Likewise, Grzankowski expresses a similar idea when he claims that states with propositional contents, unlike states with objectual contents, involve predication and can be evaluated for truth, accuracy, satisfaction, etc.:

One important point of contrast between [states with propositional contents and states with non-propositional contents] involves predication. Notice that states such as belief and other propositional attitudes are canonically ascribed with complete sentences in the object position of the verb, e.g. 'John believes that grass is green'. When one, say, loves that grass is green or believes that grass is green, one takes grass to have a certain property, to wit, greenness. In some sense, one predicates greenness of grass. (Grzankowski 2013, 1124)

Although there is plenty of disagreement concerning the nature of propositional attitudes, it is relatively widely agreed that whatever else can be said about them, they are mental states that have propositional content and hence are evaluable for truth, 
accuracy, satisfaction, and so on. (Grzankowski 2013, 1124, footnotes suppressed)

Grzankowski highlights two features of propositional contents that are closely related to saying that something is the case: predicating a property and being assessable for truth, accuracy, or satisfaction. On the face of it, these two features of propositional contents are necessarily co-extensive with saying that something is the case, the feature that I take to be definitive of contents with a propositional character. A content involves predication just in case it says that something is the case, and a content is assessable for truth, accuracy, or satisfaction just in case it says that something is the case.

There is a wrinkle, however: What exactly truth, accuracy, and satisfaction amount to is an open question, and arguably one about the deep nature of intentionality. Some views of the nature of intentionality might have no room for such notions (see Mendelovici, 2018, chs. 1 and 9). So, it might turn out that a content says that something is the case without being assessable for truth, accuracy, or satisfaction. We can avoid this wrinkle by replacing talk of being assessable for truth, accuracy, or satisfaction with talk of appearing to be assessable for truth, accuracy, or satisfaction. Intentional states with propositional characters are such that it at least seems to make sense to characterize them as true or false, accurate or inaccurate, or satisfied or unsatisfied. They need only have a truth-assessable character, not a truthassessable nature.

I've distinguished two ways of understanding what it is for a content to be propositional or objectual and two resulting ways of understanding propositionalism and objectualism. This establishes that the deep and shallow pairs of views are conceptually distinct. But, one might wonder, does this distinction mark out a real difference? The manner in which participants of the debate switch between ways of speaking might suggest that the deep views are equivalent to their corresponding shallow views. In the remainder of this section, I will argue that deep propositionalism and shallow propositionalism do not a priori entail each other, and neither do deep objectualism and shallow objectualism. If this is right, then the deep and shallow views need not stand and fall together, at least in principle. I will explore more nuanced relations between the deep and shallow views in section 5 .

Consider first whether shallow propositionalism a priori entails deep propositionalism. Here is one way that shallow propositionalism could turn out to be true while deep propositionalism is false: Suppose that all contents say that something is the case, but, metaphysically speaking, they are all properties of a special kind, properties of being in a world contained in a certain set of possible worlds. This view of the nature of content takes contents to have a proprietal (and hence non-propositional) nature, so, on it, deep objectualism is true (of course, there are other views of the deep nature of contents involving possible worlds that count as versions of deep propositionalism). But since it takes all contents to say that something is the case, it takes all contents to have a propositional character, and so, on it, shallow propositionalism is true. Another example of a view combining deep objectualism and shallow propositionalism is the view that all contents are objects, say, simple ideas in the mind of God, and that all contents say that something is the 
case. These examples show that shallow propositionalism does not a priori entail deep propositionalism. They are also examples of cases in which deep objectualism is true and shallow objectualism is false, so they also show that deep objectualism does not a priori entail shallow objectualism. ${ }^{5}$

Now consider whether deep propositionalism a priori entails shallow propositionalism. Here is a case in which deep propositionalism is true and shallow propositionalism is false: Suppose all contents are identified with sets of possible worlds. Suppose, further, that there are contents with objectual characters, which are also identified with sets of possible worlds. For example, the content Eleni might be identified with the set of possible worlds in which Eleni exists. Since, on this view, all contents have a propositional nature but at least some contents fail to have a propositional character, it is a view on which deep propositionalism is true and shallow propositionalism is false. Of course, one might complain that this view conflates the contents Eleni and Eleni exists, which might be reason to reject the view. But it could also be that this view is true and the impression that Eleni and Eleni exists are distinct contents is an illusion. In any case, even if this view is false, it is still a possible view, and so it still serves to show that deep propositionalism does not a priori entail shallow propositionalism. This example is also a case in which shallow objectualism is true and deep objectualism is false, so it also shows that shallow objectualism does not a priori entail deep objectualism.

The reason why the deep views and the shallow views do not mutually a priori entail each other is that the deep views only tells us what kind of thing contents are, leaving open the question of how things of the relevant kind are associated with contents of a certain character. A view of the nature of content might identify contents or certain kinds of contents with sets of possible worlds, clusters of abstract properties, concrete objects, possible objects, abstract ideas, or something else. But any of these items might be identified with contents with either objectual or propositional characters. Of course, some kinds of items that we might identify with contents might be more naturally associated with certain kinds of characters than others. For example, concrete objects are more naturally associated with contents with a certain kind of objectual character. However, as we have seen, there are possible combinations of views on which the nature of contents doesn't bear this kind of affinity to their characters. In any case, if the preceding is right, deep propositionalism (objectualism) and shallow propositionalism (objectualism) are not a priori equivalent.

\section{What we care about is the shallow debate}

I've distinguished two ways of understanding what it is for a content to be propositional or objectual and two resulting ways of understanding propositionalism and objectualism. Both

\footnotetext{
${ }^{5}$ Grzankowski $(2013,1126)$ agrees that (shallow) propositionalism might still be true even if all contents were non-propositional entities like properties (Lewis 1979) or open sentences (Burge 1977), so long as these entities are truth-evaluable.
} 
the deep versions and the shallow versions of the views are worth discussing, but I want to recommend understanding the debate between propositionalism and objectualism as a debate over the shallow versions of the views. This is not to say that this is the view that particular authors have in mind. It is quite possible that some authors have deep views in mind or views that incorporate claims from both the deep and the shallow views. My claim is only that, for the most part, what we really care about in this debate are the shallow versions of the views.

Let us consider what the truth of propositionalism and objectualism, as standardly conceived, might naturally be taken to hang on. Suppose that it turned out that intentionality was not a relation to distinctly existing entities that play the roles of contents, but rather an adverbial modification of intentional subjects or intentional states, as some have argued (Kriegel 2007, 2011, Pitt 2009, Mendelovici 2018). On these non-relational views of intentionality, contents are psychological types, ways of representing, or aspects of intentional states, rather than entities existing distinctly of our intentional states that we grasp, entertain, or otherwise represent. If it turned out that a non-relational view of intentionality was true, then deep propositionalism and deep objectualism would both be false, since both assume a relational view of intentionality. However, I doubt that this would be taken to resolve the debate over propositionalism. This does not, for instance, tell us whether the state of loving Eleni involves representing Eleni as being some way. If this is right, then propositionalism and objectualism are not concerned with the deep nature of intentionality, and so should not be understood as deep propositionalism and deep objectualism.

Even assuming a relational picture of intentionality, and hence that either deep propositionalism or deep objectualism is true, the truth of propositionalism and objectualism, as standardly conceived, does not depend on whether the items we identify with contents have a propositional or an objectual nature. Suppose all contents are special kinds of properties, the properties of being in a world contained in a certain set of possible worlds. Even though this view of the nature of content takes contents to have a proprietal nature, it is compatible with both propositionalism and objectualism as standardly conceived. These contents with a proprietal nature might all be identified with contents with a propositional character, or some might be identified with contents of an objectual character. Although on such a view, deep objectualism is true, it wouldn't settle the debate between propositionalism and objectualism, as standardly conceived. For example, it would not determine whether the state of loving Eleni represents just Eleni or Eleni is $F$, for some F.

Views about whether the characters of contents are propositional or objectual do seem to bear on the debate between propositionalism and objectualism, as standardly conceived. Suppose it turns out that there are states with an objectual character. For example, suppose the state of loving Eleni does not represent that something is the case. Such a state would be a counterexample to propositionalism, as standardly conceived, and would establish objectualism. Likewise, suppose it turned out that some fears had contents with a proprietal character, like clown, rather than contents with a propositional character, like a clown attacks $m e$. This case would provide a counterexample to propositionalism and establish 
objectualism. If, instead, it turns out that all intentional states had contents with a propositional character, like grass is green, then this would be taken to establish propositionalism.

If all this is right, then what we really care about when we care about the debate between propositionalism and objectualism is not the deep versions of the views, but the shallow versions.

\section{The autonomy of the shallow debate}

As I argued in the previous section, the debate over propositionalism and objectualism, which from hereon I will understand as shallow propositionalism and shallow objectualism, respectively, isn't over the nature of content. Propositionalism doesn't claim that contents are propositions or even proposition-like entities, and objectualism doesn't claim that, say, objects, like the concrete object Eleni, literally are parts of contents. This should be a welcome consequence for those who want to eschew metaphysical debates, particularly since both the claim that there are propositions and the claim that real concrete objects can enter into our intentional contents are controversial. But this hasn't yet shown that the best or only way to resolve the debate between propositionalism and objectualism isn't to investigate the nature of intentionality. While the truth of deep propositionalism or deep objectualism doesn't a priori entail any view in the shallow debate, it might be suggestive of one view or the other, or other views of the nature of content might a priori entail one of the shallow views.

This section argues that the debate between propositionalism and objectualism can in fact be carried out fairly autonomously from debates concerning the nature of intentionality. I will argue for this claim by arguing that there are natural ways of engaging in the debate that do not employ considerations pertaining to the nature of content and that when views of the nature of content and the views of the character of content conflict, it is often the case that views of the character of content take precedence.

Let us first consider the natural ways of investigating whether any given content has a propositional or objectual character. Questions concerning the character of content are not metaphysical questions but rather empirical questions about what specific kinds of contents we do or can represent. Accordingly, the natural ways of investigating the character of content, and hence the natural way of finding out whether propositionalism or objectualism is true, are broadly empirical.

Recall that one way of investigating the superficial character of content is through introspective observation. For example, we can at least sometimes tell through introspection that we are thinking that grass is green rather than the snow is white. Many views concerning the character of contents can be justified by this kind of introspection, either fairly directly or somewhat indirectly. Views about the content of the token conscious intentional states subjects are in can often be fairly directly justified by those subjects' introspective observations of this sort. For example, the view that I am now thinking the content Santa 
Claus is jolly is a (fairly uninteresting) view about the character of a certain intentional state that can be directly justified by introspection. Other views about the character of content are a few inferential steps removed from views that can be justified by introspective observation. The view that human beings can think about non-existent objects is an example of such a view. We arrive at such a view by considering various token intentional states that we can have (e.g. a thought with the content Santa Claus is jolly) and considering various nonintentional facts about the world (e.g. that Santa Claus does not exist). Another example of a view that is indirectly justified by introspective observation is the view that the intentional contents of color experiences can be plotted in a three-dimensional space with various structural properties. We arrive at this kind of view by considering multiple token intentional states of multiple subjects, which we find out about by considering subjects' verbal reports of their introspectively accessible color experiences, e.g. of their perceived similarities or differences. As these examples illustrate, many views about the character of content can be justified either directly or indirectly by introspective observation or introspective observation in combination with other evidence.

Introspective observation has been used to argue for objectualism (see e.g. Montague 2007, p. 507). It really seems that we can think the mere content cat. Just as we can think Whiskers is a cat and Cats have tails, it seems that we can just think cat without thinking that anything is a cat or anything about cats. That we can think cat is arguably clear to introspection in the same way as that we can think Santa Claus is jolly is clear to introspection.

Recall that another way of finding out about the superficial characters of intentional states is through their psychological roles, including roles in generating further intentional states and behaviors. For example, a perceptual experience representing a book on a table is likely to lead to a belief that a book is on a table. We can draw conclusions about what a given intentional state represents from evidence concerning that intentional state's psychological role.

Considerations pertaining to psychological role have been used to argue for both propositionalism and objectualism. Sinhababu (2015) argues for propositionalism as follows: Propositionalism, but not objectualism, can explain why certain intentional states give rise to certain motivations and behaviors. Compare Katie and Tyler, who both have an intense desire for Bumper the Goldfish. Katie is motivated to adopt Bumper as a pet, while Tyler is motivated to eat him. Objectualism about desires ascribes the same contents to Katie and Tyler's desires, the content Bumper, but this doesn't make sense of their different motivational states. Propositionalism, in contrast, can make sense of the difference in motivation: The content of Katie's desire is I adopt Bumper, while the content of Tyler's desire is I eat Bumper, both of which are contents with propositional characters.

Thagard (2006) uses considerations of psychological role to argue for objectualism about desire. He argues on the basis of empirical considerations that many animals that cannot represent relations or themselves can nonetheless desire food. So, their desire for food 
must have the objectual content food rather than a propositional content like I have food. He argues that while we have the capacity for desires with a propositional content, many of our desires are similar to those of such animals in that their contents are objectual.

In Mendelovici 2013a and 2014, I also used considerations pertaining to psychological role to argue that moods have objectual contents. I argue that the specific qualities of moods, e.g. happiness, sadness, irritation, etc., behave as we would expect contents of a proprietal character to behave: They bind with contents with object-like characters, like John, to yield contents with propositional characters, like John is irritating. This suggests that the qualities of moods are contents, rather than, say, mere phenomenal characters, and, further, that they have proprietal characters, making them objectual contents.

My aim here is not to assess these arguments, but to illustrate the kinds of arguments and evidence that naturally bear on the debate between propositionalism and objectualism, assuming that we construe it as a view about the character of content. To resolve this debate, we need to find out what kinds of contents we can entertain, and the natural way of finding out what kinds of contents we can entertain is to consider introspective evidence and the psychological roles of intentional states.

Even though propositionalism and objectualism, as I recommend understanding the views, don't make claims about the nature of contents, and even though the natural way of approaching the debate is through the broadly empirical study of psychological phenomena, views about the nature of content can nonetheless have implications for the debate. In section 3 , I argued that the truth of deep propositionalism or deep objectualism would not settle the debate between the shallow versions of the views, but this does not mean that views of the nature of content cannot interact with the shallow debate. For instance, some views of the nature of content specify not only what kind of entity contents are to be identified with but also how these entities are supposed to map onto contents of a certain character. Compare: The mind-brain identity theory claims that mental states are identical to brain states. As stated, the theory does not tell us which mental states are identical to which brain states. ${ }^{6}$ But it can be supplemented with such an account. Indeed, there is a natural way of mapping mental states onto brain states: Mental states are identical to the brain states they are correlated with. In the same way, a view of the nature of content might include a specification of how contents of a certain character map onto the entities it wants to identify with contents. Such a view would have implications for which contents we can entertain. For example, a possible worlds view that maps contents onto the possible worlds in which they are true implies that there are no contents of an inconsistent character, that there is only one content corresponding to all logical truths, and that there are no contents of an objectual character. Even if a view of the nature of content doesn't specify a mapping between intentional contents and the items it wants to identify with them, it might be combined more naturally with some such mappings than with others. All this shows that, even though both positions in

\footnotetext{
${ }^{6}$ This is what David Bourget calls the "mapping problem". See Bourget and Mendelovici 2014.
} 
the deep debate are compatible with both positions in the shallow debate, certain views of the nature of content have implications for the shallow debate.

While I don't want to deny the relevance of considerations of the nature of content to views of its character, I want to suggest that in cases where our views about its nature conflict with our views about its character, the views about its character tend to take precedence and, further, that this is often as it should be. In this section, I've outlined various broadly empirical ways of investigating the character of content. Much of the evidence for shallow views is fairly uncontroversial observational evidence, or only a few step removed from such evidence. For instance, our evidence for thinking that we can entertain contents corresponding to things that happen not to exist, such as the content Santa Claus is jolly, is largely fairly indisputable introspective observational evidence. That we can entertain such contents is practically a datum that any deep or shallow theory must accommodate. Although a view of the nature of content could in principle motivate us to revise our belief that we can entertain such contents, this scenario is unlikely. It is more likely is that we would conclude that the view of the nature of content is mistaken. All this is as it should be: Intentionality is a phenomenon that we observe and want to explain. A theory that doesn't accommodate our observations is empirically inadequate, which means it is false.

The disjunction problem for tracking theories of intentionality provides another example of a conflict between views of the nature of intentionality and views of its character. Causal theories of intentionality are views of the nature of intentionality on which intentionality is a special kind of causal relation between mental representations and the items or properties that cause them. One challenge for causal theories is that of distinguishing the items that can cause a mental representation that are part of or instances of its content from the items that can cause it but that are not part of or instances of its content. For example, suppose the mental representation HORSE can be caused by both horses and malnourished cows on dark nights. If a causal theory's favored causal relation holds between the representation HORSE and both horses and malnourished cows on a dark night, then the theory inappropriately predicts that HORSE represents the disjunctive content horse or malnourished cow on a dark night. ${ }^{7}$ This is supposed to be a reason to reject the theory. Notice that the disjunction problem is an example of a conflict between views of the nature of intentionality (causal theories) and views of the character of intentional contents (e.g. that HORSE represents the non-disjunctive content horse). The point I want to make for present purposes is that the disjunction problem is considered to be a problem for the views of the nature of intentionality, rather than a problem for the conflicting view of the character of intentional contents. In the case of the disjunction problem, considerations concerning the character of content take precedence over theories of the nature of intentionality. Again, all this is as it should be: A theory that faces the disjunction problem is false not because ascribing disjunctive contents is in itself problematic but rather because we have strong

\footnotetext{
${ }^{7}$ See Fodor (1987) for discussion of the disjunction problem and this example.
} 
independent evidence for thinking we do not represent disjunctive contents in the relevant cases. A theory of intentionality that does not accommodate this evidence is empirically inadequate, and hence false.

If all this is right, then, even though views about the nature of intentionality can have implications for views about the character of contents, the character of content can be investigated fairly independently of its nature. The natural methodology for investigating the character of content is broadly empirical, and in the event of a conflict between views of the character of content and views of the nature of intentionality, views of the character of content tend to and often should take precedence. ${ }^{8}$

All this suggests that we should view arguments from the deep nature of contents to propositionalism or objectualism with some suspicion. One such argument involves arguing for propositionalism by arguing that objectualism cannot adequately account for intentional states about objects that don't exist. ${ }^{9}$ In the case of intentional states about objects that do exist there are good candidates for identification with their contents: existing objects. For example, take the intentional state of liking Eleni. The objectualist might claim that the content of this state is Eleni herself, the real concrete existing object. But what, then, is the content of the intentional state of liking Santa Claus? There is no good candidate existing object to identify with its content. Propositionalism avoids this problem by taking all contents to be propositional. The content of the state of liking Santa Claus is a proposition about Santa Claus, like the proposition that Santa Claus is jolly. Even though Santa Claus does not exist, the proposition exists, so propositionalism provides a good candidate entity with which to identify the content of the state of liking Santa Claus. ${ }^{10}$

I want to suggest that this argument should be viewed with suspicion because it moves

\begin{abstract}
${ }^{8}$ I have argued for and appealed to the precedence of views of the character of introspectively observable intentional states over views of their nature in various places. Mendelovici 2013b and 2016 argue for the (shallow) view that non-contrived cases of reliable misrepresentation are possible for creatures like us, that this view is incompatible with (deep) views of the nature of intentionality on which intentionality is a tracking relation, and, therefore, that tracking theories of intentionality should be rejected. Similarly, Mendelovici 2010, ch. 5 and 2018, ch. 3 argue for the (shallow) view that there are actual non-contrived cases of reliable misrepresentation, that this view is incompatible with tracking theories of intentionality, and, therefore, that tracking theories should be rejected. Mendelovici 2018, ch. 9 argues that various kinds of (deep) views of the nature of contents should be rejected because they have an inventory problem: They do not make space for all the intentional states that we manifestly can enjoy. In other words, they do not accommodate certain (shallow) facts about what intentional states we can have. Finally, Mendelovici 2010, ch. 8 and Mendelovici and Bourget 2013 argue that tracking theories that reject claims about the characters of intentional states that they cannot accommodate employ an unsound methodology, one that is not naturalistic in spirit.
\end{abstract}

${ }^{9}$ See Grzankowski (2013), Ben-Yami (1997), and Sainsbury (2010) for discussions of this argument. See also Prior $(1971,130)$ for discussion of a puzzle that naturally leads to this kind of argument and Lewis (1979) for a related argument based on the possibility of intentional states with non-specific contents.

${ }^{10}$ Grzankowski (2013) discusses this argument in detail, arguing that objectualism has greater resources than is standardly acknowledged to account for objectual contents corresponding to things that don't exist. 
from claims about the deep nature of contents to claims about its superficial character. Here is a rational reconstruction of the argument that makes the transition obvious:

(P1) If objectualism is true, then there are contents with an objectual character.

(P2) Contents with an objectual character have an objectual nature.

(P3) Therefore, if objectualism is true, then there are contents with an objectual nature. (P1, P2)

(P4) But there are no good candidate contents with an objectual nature to identify with the contents of intentional states purportedly about objects that don't exist.

(C) Therefore, objectualism is false. (P3, P4)

(P2) is problematic, allowing us to move from claims about objectual characters to claims about objectual natures. This claim assumes a kind of affinity between the character and nature of content. But if the claims of this chapter are correct, we cannot take such an affinity for granted. Contents with an objectual nature might have a propositional character, and contents with a propositional character might have an objectual nature. So, the argument can be blocked by rejecting (P2).

Even if this argument were supplemented with an argument for (P2), we might still have reasons to doubt its conclusion if we have good empirical evidence for objectualism. What we would have would be an incompatibility between a view of the nature of content and a view of the character of content. Although it is possible that our reasons for believing objectualism are mistaken, we might more reasonably suspect that the mistake lies in our supplemented argument against objectualism.

\section{$6 \quad$ The debate over singular contents}

Similar points as have been made in the previous sections can be made concerning other debates in the philosophy of mind. One closely related debate is that over singular contents. Some mental states seem to have singular contents in that they seem to involve particular objects. For example, the perceptual experience of David walking might seem to involve a particular individual, David, as part of its content. An alternative view is that such contents in fact represent existentially quantified contents. The perceptual experience of David walking might be said to represent a content such as there is an object with such-and-such features that is walking. The debate is over whether such mental states that appear to have singular contents in fact have singular contents, or whether, instead, they have existentially quantified contents. While the view that there are singular contents is supported by the phenomenology of the relevant states, the view is unattractive because it is just not clear how particular objects can enter into our mental contents. ${ }^{11}$

${ }^{11}$ See, e.g. Schellenberg (2010) and Montague (2011) for discussion. 
There are two ways of understanding this debate: as a debate over the deep nature of the contents of certain states, and as a debate over their superficial characters. The debate concerning deep nature is over whether there are contents with a singular nature, which are contents that literally include objects in them as parts. The debate concerning the character of contents is over whether there are contents with a singular character, which are contents involving object-like characters rather than existential-construction-like characters.

Distinguishing these two debates allows us to resolve the tension between the case for and against the view that there are singular contents. We can say that there are contents with a singular character without committing to contents with a singular nature. This position respects the phenomenological considerations without committing to any potentially unattractive metaphysical claims. ${ }^{12}$

\section{Conclusion}

When we point to a piece of furniture and ask, "What is this?", there are two questions we might be asking: We might be asking whether it is a physical item, a functional item, a response-dependent item, or whether it has some other kind of nature. Or we might simply be asking whether it is, for instance, a table, a couch, or a chair. Similarly, when we ask of an intentional state, "What is this state's content?", we might be asking whether the content is a set of possible worlds, an ordered pair of objects and properties, an adverbial modification of subjects, or whether it has some other nature. Or we might simply be asking whether it is, e.g., the grass is green content, the snow is white content, or the elephants are dancing on the table content. The first kinds of question in both the furniture and the content case are deep, inquiring into the metaphysical nature of an item, while the latter two are shallow, inquiring into the superficial features that characterize it as the particular item of its general kind (furniture or content) that it is.

Interestingly, unlike in the case of furniture, largely the same set of expressions can be used to characterize both the deep nature of contents and their superficial characters. For example, "Intentional state M represents Justin Trudeau" can be taken to mean that M's content is identical to Justin Trudeau, the flesh-and-blood person, which is a claim about M's deep nature. Or it can be taken to mean that $\mathrm{M}$ has the Justin Trudeau content, rather than the Barack Obama content or the pink jelly beans content, which is a claim about M's superficial character. In the same way, "All contents are propositional" can be understood as stating that all contents are identical to items of a propositional form, which is a claim about their deep natures. Or it can be interpreted as stating that all intentional states represent that such-andsuch is the case, which is a claim about the superficial character of intentional states and their contents. In light of the fact that the same expressions, including the terms "propositional" and "objectual," can be used to describe both the deep natures of contents and their superficial characters, it is especially important to be clear on which interpretation we have in

\footnotetext{
${ }^{12}$ Mendelovici 2018, ch. 7 develops a view like this.
} 
mind.

In this chapter, I suggested that the distinction between deep nature and superficial character can help clarify the debate between propositionalism and objectualism. I distinguished deep and shallow versions of the two views, and recommended understanding the debate as one over the shallow versions. I argued that the study of the superficial character of content, and hence the debate between propositionalism and objectualism, is fairly autonomous from the study of the nature of content, and that, as a result, arguments drawing conclusions about the character of content from its nature should be viewed with suspicion. I briefly suggested that related claims can be made in the debate over singular contents. As the case of singular contents nicely illustrates, teasing apart the deep views from the shallow views can make room for attractive combinations of views that might otherwise be neglected. ${ }^{13}$

\section{Bibliography}

Ben-Yami, Hanoch (1997). Against characterizing mental states as propositional attitudes. Philosophical Quarterly 47 (186):84-89.

Bourget, David \& Mendelovici, Angela (2014). Tracking Representationalism. In Andrew Bailey (ed.), Philosophy of Mind: The Key Thinkers. Continuum. pp. 209-235.

Brewer, Talbot (2006). Three dogmas of desire. In T. D. J. Chappell (ed.), Values and Virtues: Aristotelianism in Contemporary Ethics. Oxford University Press.

Burge, Tyler (1977). Belief de re. Journal of Philosophy 74 (6):338-362.

Dretske, Fred (1980). The intentionality of cognitive states. Midwest Studies in Philosophy 5 (1):281-294.

Fodor, Jerry A. (1987). Psychosemantics: The Problem of Meaning in the Philosophy of Mind. MIT Press.

Goff, P. (2017). Consciousness and Fundamental Reality. Oxford University Press.

Grzankowski, Alex (2012). Not All Attitudes are Propositional. European Journal of Philosophy. DOI: 10.1111/j.1468-0378.2012.00534.x.

Grzankowski, Alex (2013). Non-Propositional Attitudes. Philosophy Compass 8 (12):11231137.

Kriegel, Uriah (2007). Intentional inexistence and phenomenal intentionality. Philosophical Perspectives 21 (1):307-340.

\footnotetext{
${ }^{13}$ Many thanks to David Bourget, Philip Goff, two anonymous reviewers, and the audience at the Central European University's "Mind, Matter, and Consciousness" summer school for valuable comments and discussion.
} 
Kriegel, Uriah (2011). The Sources of Intentionality. Oxford University Press.

Lewis, David (1979). Attitudes de dicto and de se. Philosophical Review 88 (4):513-543.

Mendelovici, Angela (2010). Mental Representation and Closely Conflated Topics. Dissertation, Princeton University.

Mendelovici, Angela (2013). Intentionalism about moods. Thought: A Journal of Philosophy 2 (1):126-136.

Mendelovici, Angela (2013). Reliable misrepresentation and tracking theories of mental representation. Philosophical Studies 165 (2):421-443.

Mendelovici, Angela (2014). Pure intentionalism about moods and emotions. In Uriah Kriegel (ed.), Current Controversies in Philosophy of Mind. Routledge. 135-157.

Mendelovici, Angela (2016). Why tracking theories should allow for clean cases of reliable misrepresentation. Disputatio 8 (42):57--92.

Mendelovici, Angela (2018). The Phenomenal Basis of Intentionality. Oxford University Press.

Mendelovici, Angela \& Bourget, David (2014). Naturalizing intentionality: Tracking theories versus phenomenal intentionality theories. Philosophy Compass 9 (5):325-337.

Montague, Michelle (2007). Against propositionalism. Noûs 41 (3):503-518.

Perry, John (1994). Intentionality (2). In Samuel D. Guttenplan (ed.), A Companion to the Philosophy of Mind. Oxford: Blackwell, 286-295.

Pitt, David (2009). Intentional psychologism. Philosophical Studies 146 (1):117-138.

Prior, A. N. (1971). Objects of Thought. Oxford, Clarendon Press.

Putnam, Hilary (1975). The meaning of 'meaning'. Minnesota Studies in the Philosophy of Science 7:131-193.

Sainsbury, R. M. (2010). Intentionality without exotica. In Robin Jeshion (ed.), New Essays on Singular Thought. Oxford University Press. 300-318.

Schellenberg, Susanna (2010). The particularity and phenomenology of perceptual experience. Philosophical Studies 149 (1):19-48.

Sinhababu, Neil (2015). Advantages of propositionalism. Pacific Philosophical Quarterly.

Thagard, Paul R. (2006). Desires are not propositional attitudes. Dialogue 45 (1):151-156. 